\title{
Internal Jugular Vein Pseudoaneurysm Presenting as Lateral Neck Mass
}

\author{
Dinesh Mohan ${ }^{1}$, Bhavna², Pooja ${ }^{3}$, Savita $^{4}$ \\ ${ }^{1}$ Department of General Surgery, MAMC, Agroha, Hisar, Haryana, India. ${ }^{2}$ Department of \\ Radiodiagnosis and Imaging, PGIMS, Rohtak, Haryana, India. ${ }^{3}$ Department of General Surgery, MAMC, \\ Agroha, Hisar, Haryana, India. ${ }^{4}$ Department of General Surgery, MAMC, Agroha, Hisar, Haryana, India.
}

\section{PRESENTATION OF CASE}

A 71- year- old male patient who was admitted with sudden loss of consciousness followed by slurring of speech and weakness of left side of the body and swelling on left side of the neck with the previous history of cerebrovascular accident (infarct). Patient was a known case of diabetes mellitus and hypertension and atrial fibrillation

On physical examination, he was found to have a pulsatile swelling of $3 \times 1.8 \mathrm{cms}$ in the left cervical region (fig 1). The swelling was soft, compressible non-tender nonerythematous and not associated with inflammatory changes on skin over the swelling.

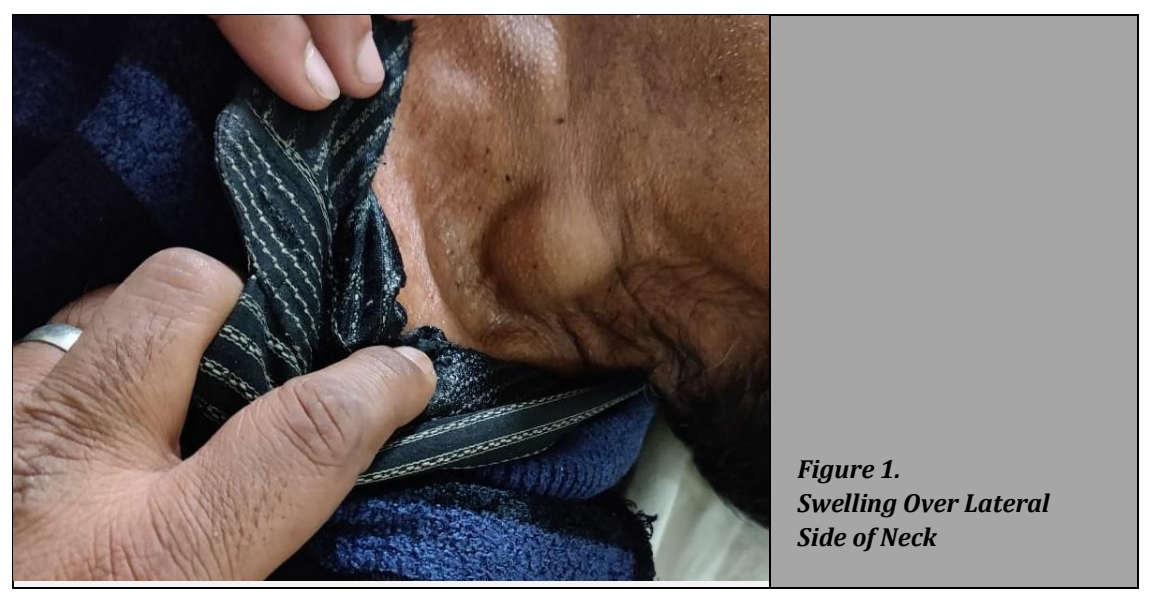

There is no past history of internal jugular vein cannulation or trauma. On examination in the supine position, the swelling was more pulsatile and in upright position, pulsatility decreased. A swelling on lateral side of neck can have a number of probable aetiologies, one of which is vascular diseases. Here we present a case of an individual with a jugular vein pseudoaneurysm associated with cardiac failure. The prominence of the pulsation of jugular vein pseudoaneurysm directly correlated with the severity of cardiac failure and the volume overload.
Corresponding Author: Dr. Dinesh Mohan, OP Jindal Resident Doctor Hostel, Room No. 204, Agroha, Hisar, Haryana, India. E-mail: dineshmohan1009@gmail.com

DOI: $10.14260 / \mathrm{jemds} / 2020 / 287$

Financial or Other Competing Interests: None.

How to Cite This Article:

Mohan D, Bhavna, Pooja, et al. Internal jugular vein pseudoaneurysm presenting as lateral neck mass. J. Evolution Med. Dent. Sci. 2020;9(15):1319-1321, DOI: $10.14260 / j e m d s / 2020 / 287$

Submission 14-02-2020,

Peer Review 24-03-2020,

Acceptance 01-04-2020,

Published 13-04-2020.

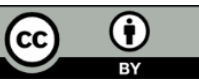




\section{DIFFERENTIAL DIAGNOSIS}

Branchial cyst, cystic hygroma, laryngocele, lymphangioma, lymphoma, tubercular lymphadenitis, inflammatory swellings.

\section{RADIOLOGICAL DISCUSSION}

The transthoracic echocardiogram reveals ejection fraction of $58 \%$, dilated left atrium ( $4 \mathrm{cms}$ ), mild concentric left ventricle hypertrophy, grade 2 left ventricle diastolic dysfunction, mild tricuspid regurgitation, and mild pulmonary artery hypertension.
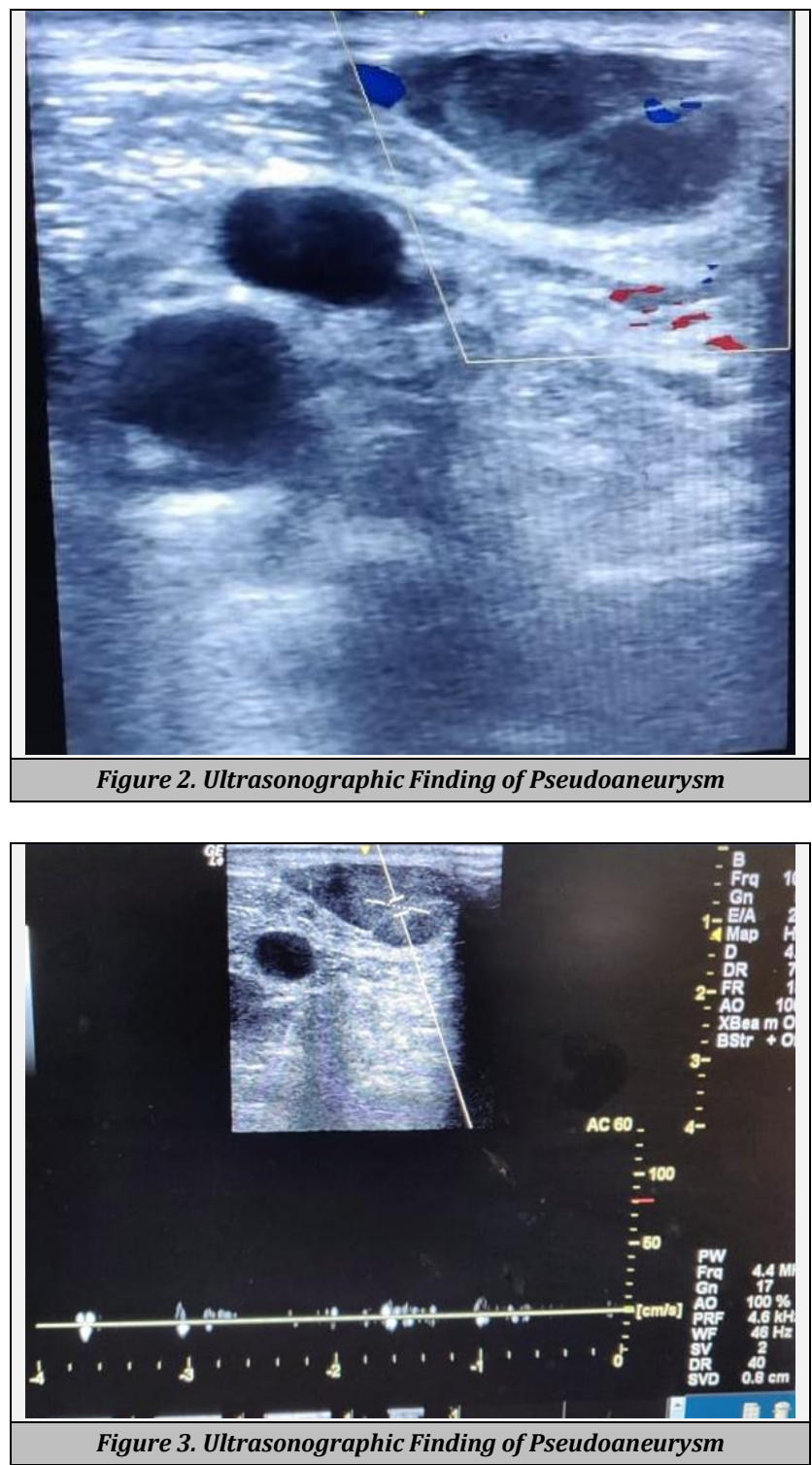

\section{DISCUSSION}

The differential diagnosis of lateral neck mass is of wide range and includes congenital abnormalities, traumatic lesions, neoplasms and infections.(1)

Detailed history and physical examination help in deciding the aetiology of a neck swelling with imaging investigation. Pulsatile neck swelling should direct towards the suspicion of vascular anomaly, on palpation of swelling if it appears as soft and compressible area a venous anomaly can be considered. If on examination it appears as vascular lesion ultrasonography can be used to confirm the diagnosis.

Both true and pseudoaneurysm are very rare clinical entities. Even if they are rare, these conditions may arise by any kind of intervention be it central venous catheter or due to previous neck injury by trauma.(2) IN patients with no history of trauma, congenital weakness and vessel wall inflammation can be a possible cause.(3,4) Tricuspid regurgitation and high central venous pressure with associated venous valve incompetence may cause pseudoaneurysm to manifest as it filled with a flood.

This patient's vascular lesion appears to be pseudoaneurysm rather than a true aneurysm as the integrity of the underlying vessel wall was intact with exception of narrow communication between vessel lumen and surrounding tissue containing the lesion. A True aneurysm involve dilation of all three layers of vessel wall without any communication with surrounding tissue.(5)

Complications of jugular vein aneurysms are thromboembolism and rupture both of which are rare.(6) These lesions do not require anticoagulation or any surgical intervention until unless there is a cosmetic concern.(7) Venous aneurysms of lower limbs, however usually present with recurrent thromboembolic episodes despite repeated anticoagulant therapies and hence should be surgically removed. $(7,8)$

Learning point: an internal jugular vein aneurysm or a pseudoaneurysm should be considered as a differential in pulsatile lateral neck mass. The size of mass can vary with underlying hemodynamic condition and regurgitation.

\section{FINAL DIAGNOSIS}

Internal jugular vein pseudoaneurysm presenting as lateral neck swelling.

\section{REFERENCES}

[1] Schwetschenau E, Kelley DJ. The adult neck mass. American Family Physician 2002;66 (5):831-8.

[2] Pollard J, Abu-Yourself M. Internal jugular vein pseudoaneurysm. Ultrasound Quarterly 2014;30 (3):2257.

[3] Gloviczki P, Dalsing M, Eklof B, et al. Handbook of Venous and lymphatic disorders. Boca Raton, FL: CRC Press, Taylor \& Francis Group 2016.

[4] Baker JB, Ingraham CR, Fine GC, et al. Pediatric jugular vein aneurysm (Phlebectasia): report of two cases and review of literature. Radiology Case Reports 2017;12 (2):391-5.

[5] Lee HY, Lee W, Cho YK, et al. Superficial venous aneurysm: reports of 3 cases and literature review. Journal of Ultrasound in Medicine 2006;25 (6):771-6.

[6] Calligaro KD, Ahmad S, Dandora R, et al. venous aneurysm: surgical indications and review of literature. Surgery 1995;117 (1):1-6. 
[7] Gillespie DL, Villavicencio JL, Gallagher C, et al. Presentation and management of venous aneurysm. Journal of Vascular Surgery 1997;26 (5):845-52.
[8] Sandstorm A, Reynolds A, Jha P. Popliteal vein aneurysm: a rare cause of pulmonary emboli. Annals of Vascular Surgery 2017;38:315.e15-e17. 